\title{
Cotton Fabric Coated with Few-Layer Graphene as Highly Responsive Surface Heaters and Integrated Lightweight E-Textiles Circuits
}

Housseinou Ba, ${ }^{* a, b}$ Lai Truong-Phuoc, ${ }^{a}$ Vasiliki Papaefthimiou, ${ }^{a}$ Christophe Sutter, ${ }^{a}$ Sergey Pronkin, ${ }^{\mathrm{a}}$ Armel Bahouka ${ }^{\mathrm{c}}$ Yannick Lafue, ${ }^{\mathrm{b}}$ Lam Nguyen-Dinh, ${ }^{\mathrm{d}}$ Giuliano Giambastiani, *a,e,f and Cuong Pham-Huu *a

a Institute of Chemistry and Processes for Energy, Environment and Health. (ICPEES), UMR 7515 CNRS- University of Strasbourg, 25, rue Becquerel, 67087 Strasbourg Cedex 02, France. E-mail: cuong.pham-huu@unistra.fr

b Present address : BlackLeaf SAS, 23 rue Paul Ristelhuber, 67100 Strasbourg, France. E-mail: hba@blackleaf.fr

c MANIPULSE, 11 rue des Chasseurs 67400, Ilkirch, France

d The University of Da-Nang, University of Science and Technology, 54, Nguyen Luong Bang, Da-Nang, Vietnam

e Institute of Chemistry of OrganoMetallic Compounds, ICCOM-CNR and Consorzio INSTM, Via Madonna del Piano, 10 - 50019, Sesto F.no, Florence, Italy. E-mail: giuliano.giambastiani@iccom.cnr.it

$f \quad$ Kazan Federal University, 420008 Kazan, Russian Federation 

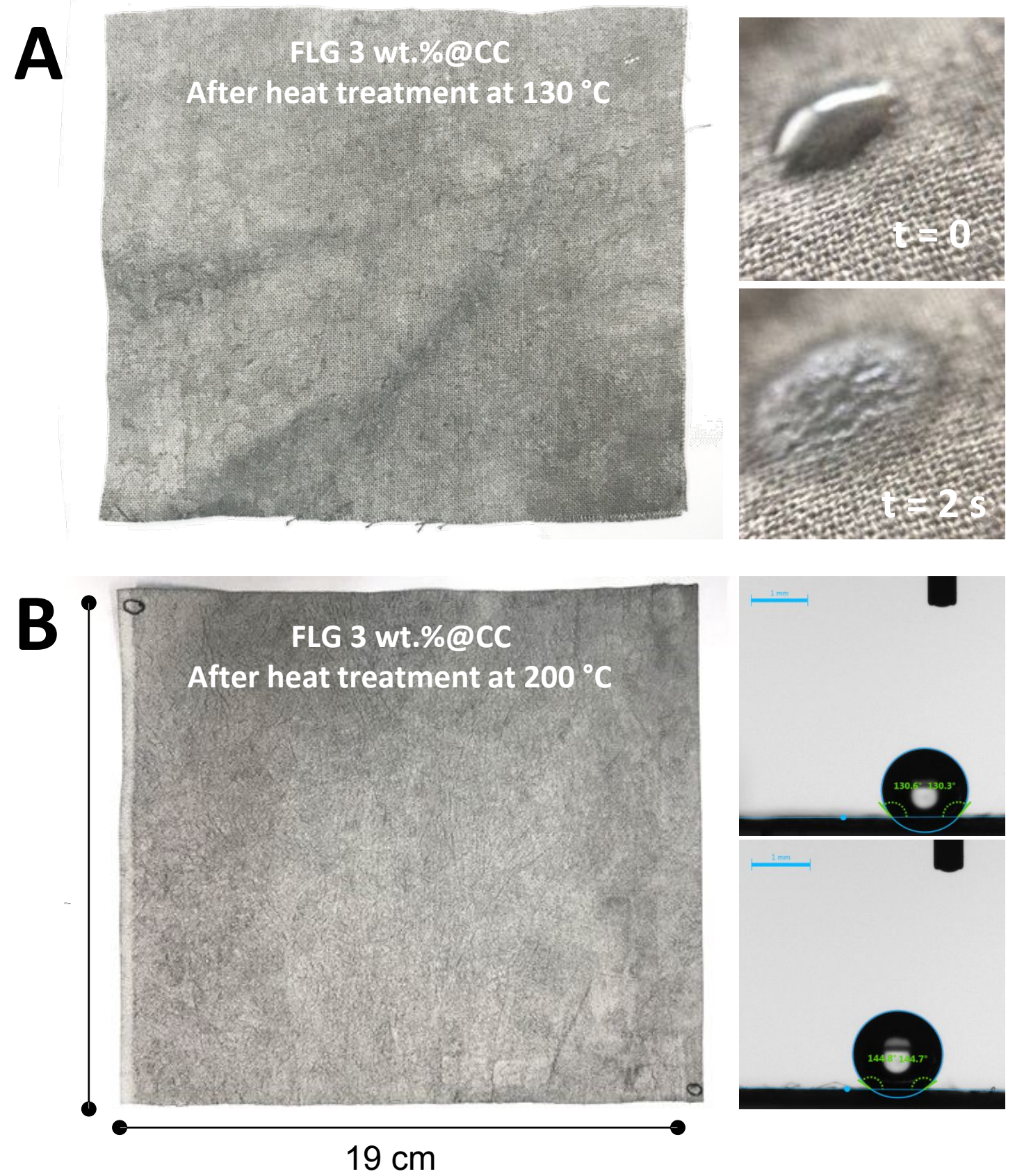

Figure S1. Digital photos and contact angle of the water droplet on the surface of the FLG@CC composites after coating followed by different thermal treatment. 

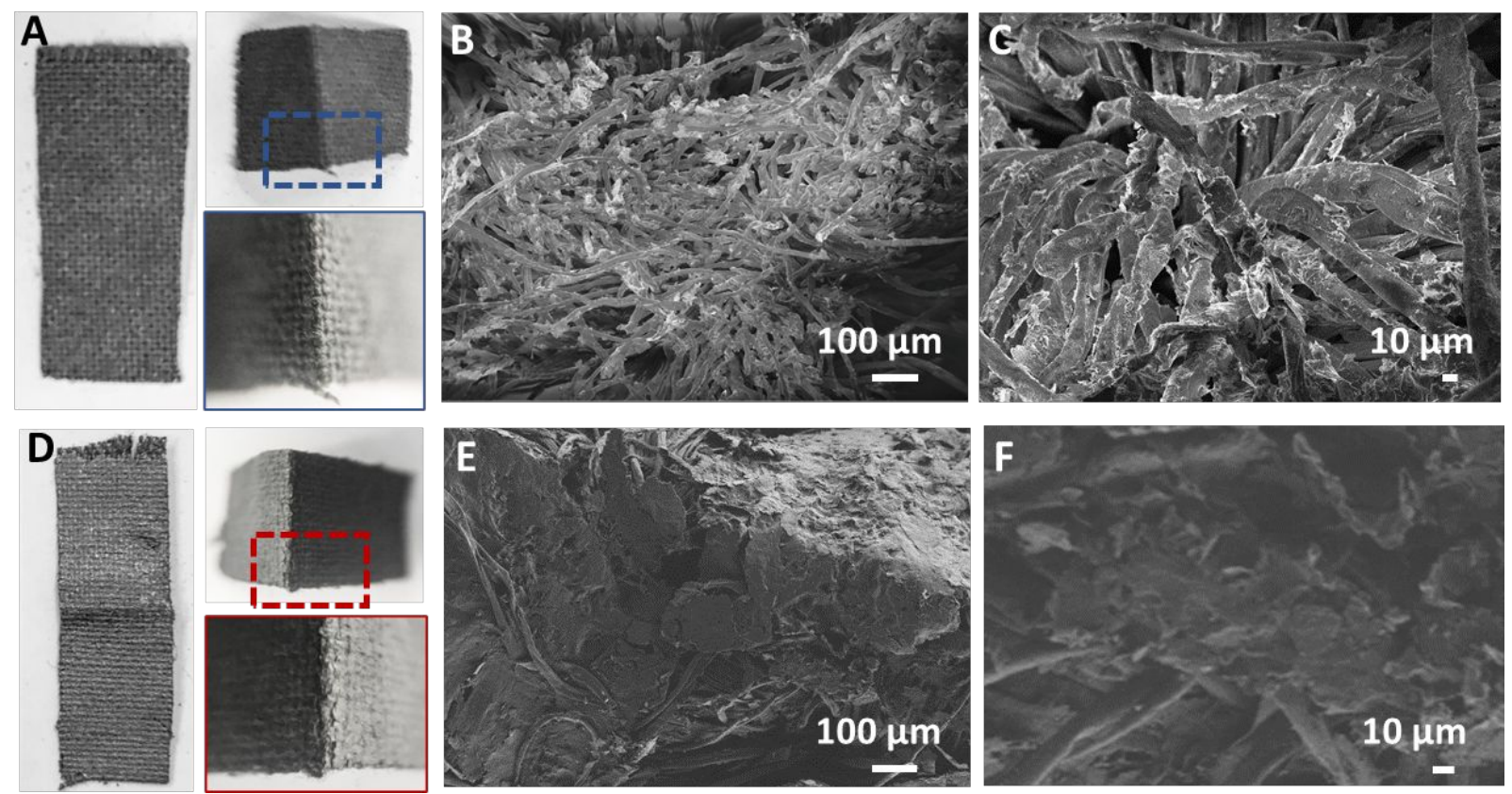

Figure S2. Digital and SEM images of the FLG@CC composites after repeated folding process. (A, B) Low loading of FLG (1 wt.\%), (C, D) High loading of FLG (6 wt. \%).

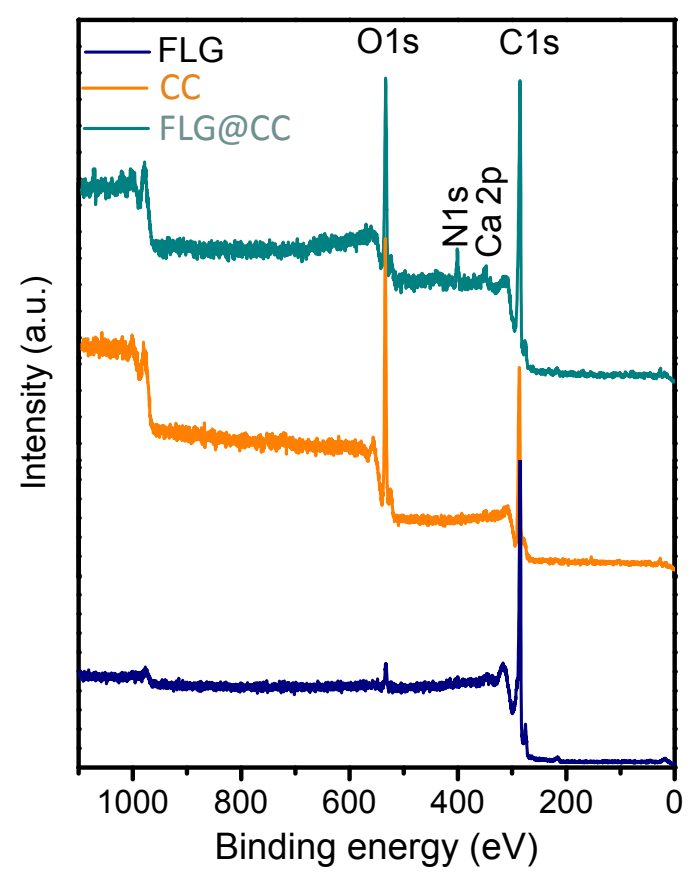

Figure S3. XPS survey spectra of the pristine FLG, cotton cloth (CC) and FLG@cotton cloth (FLG@CC) composite. 


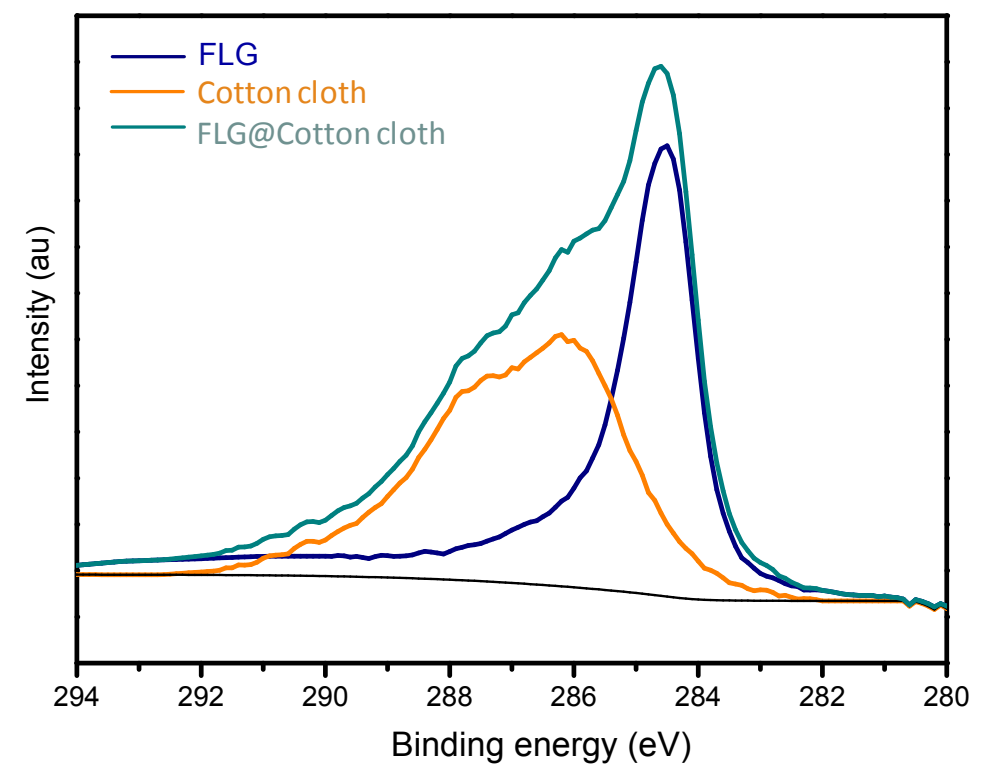

Figure S4. XPS C1s spectra of the FLG, cotton cloth and FLG@cotton cloth.
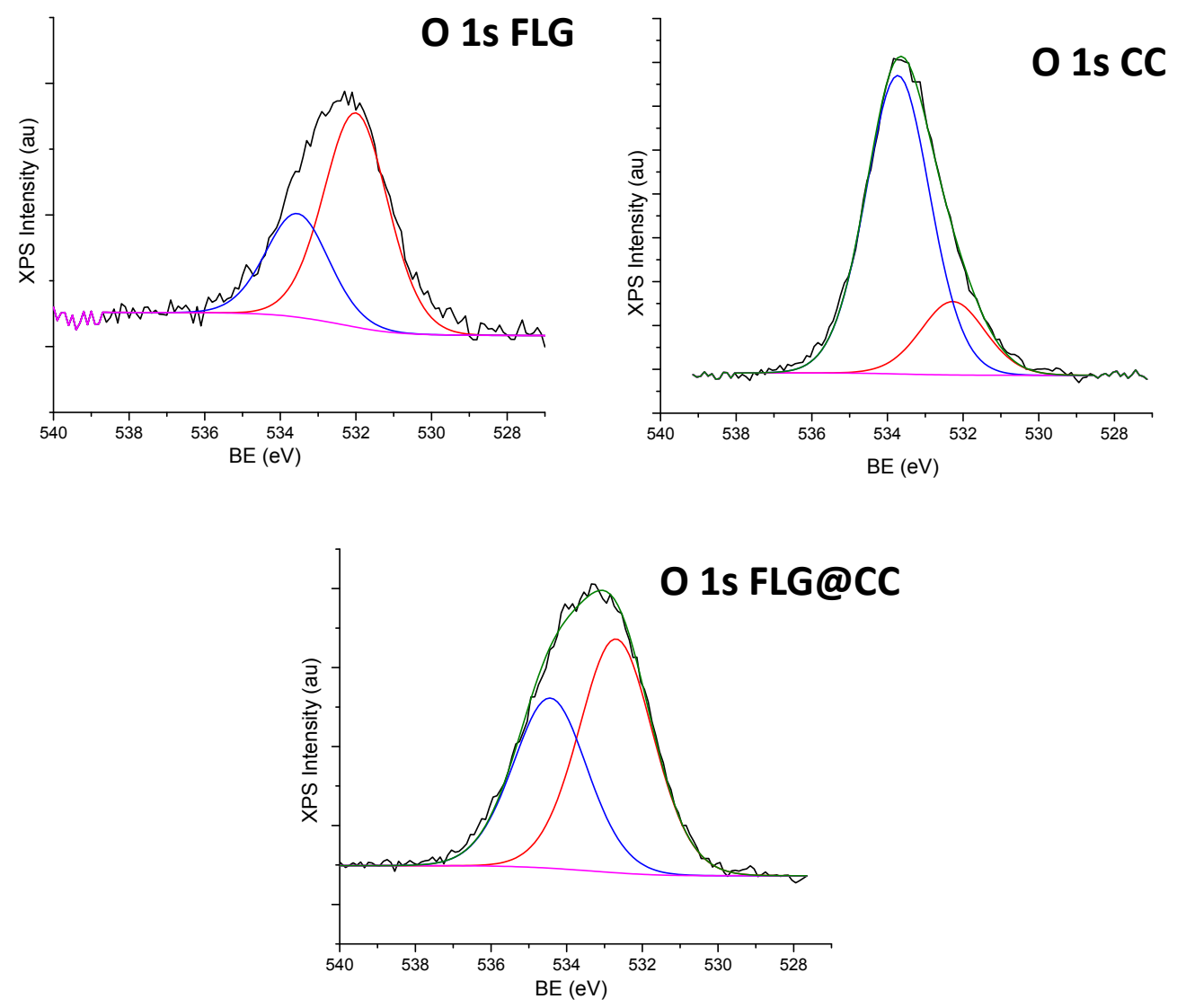

Figure S5. High-resolution XPS O1s spectra of the FLG, cotton cloth and FLG@cotton cloth. 

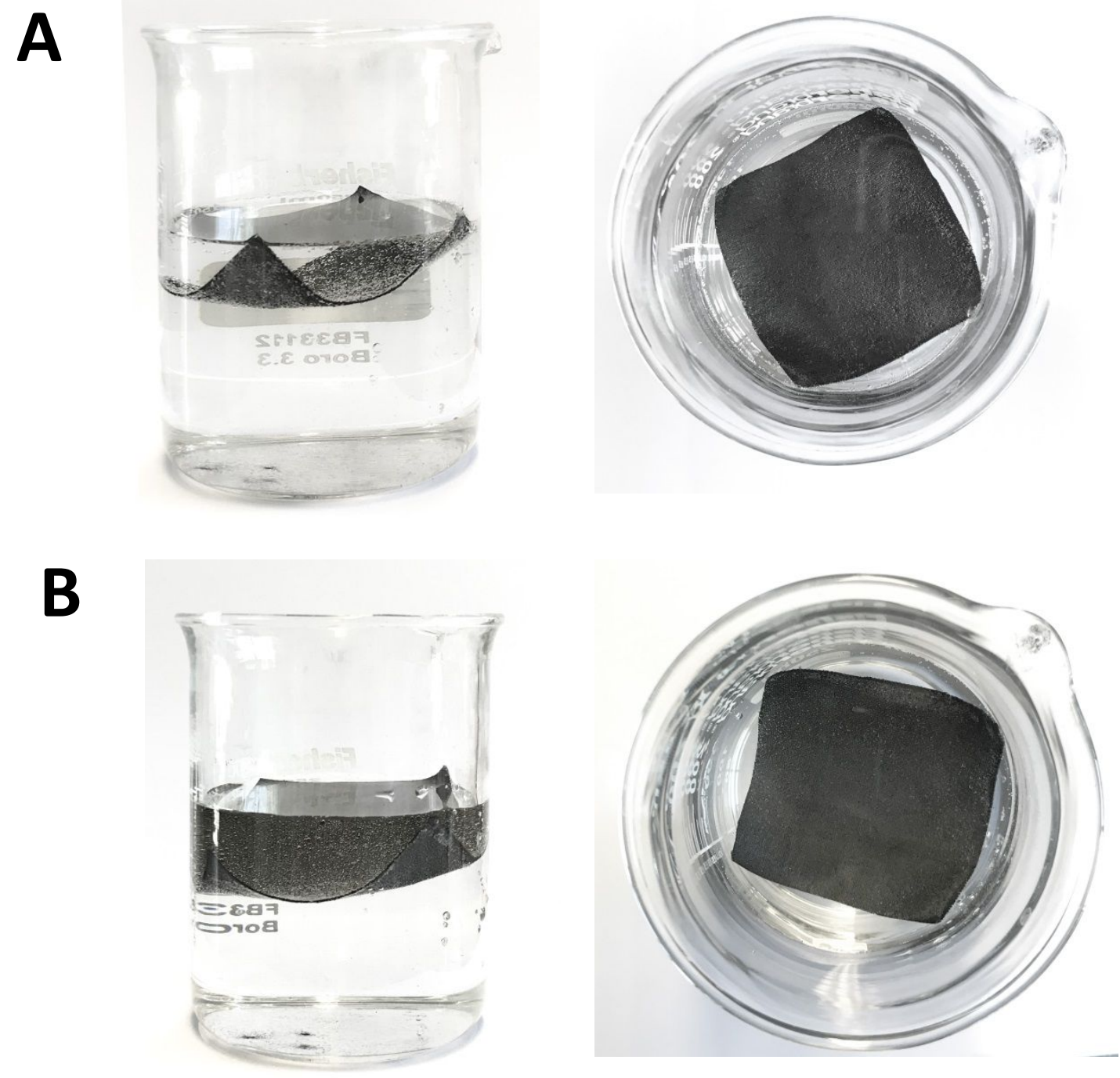

Figure S6. Digital photos of the (A) FLG@CC composite immersed inside a mixture of ethanol:water (20:80 v:v \%) and (B) the same after sonication for 30 minutes. The absence of any FLG residue inside the supernatant solution indicates the high mechanical anchorage of the FLG film on the cotton cloth surface. 

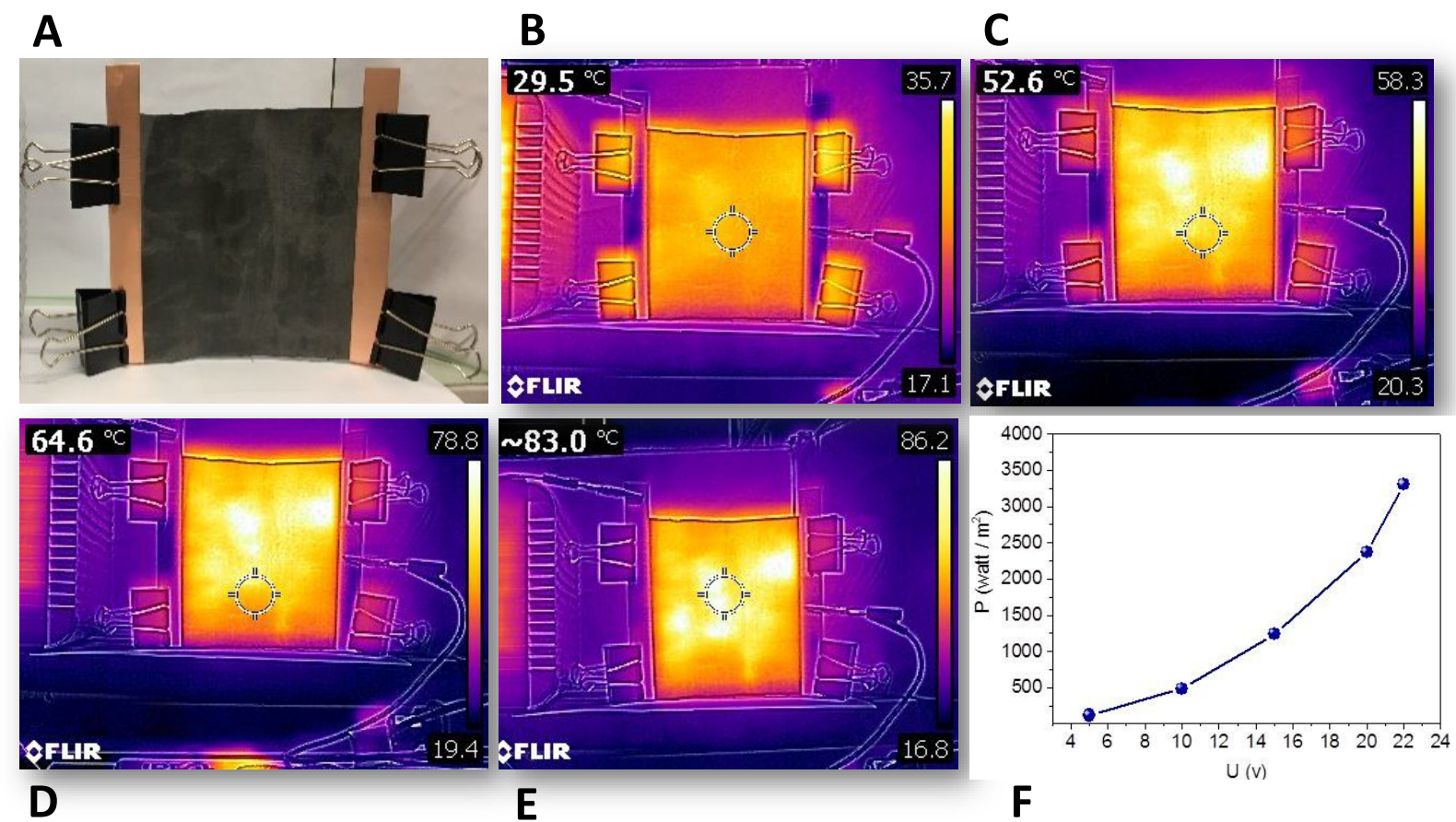

Figure S7. Thermal behavior of the FLG@cotton cloth (8 wt. \% loading) under different applied voltage: (A) Digital photo of the device. Thermal images of the FLG@CC sample at different applied voltage: (B) $5 \mathrm{~V}$, (C) $10 \mathrm{~V}$, (D) $15 \mathrm{~V}$, (E) $22 \mathrm{~V}$. (F) Corresponding specific power as a function of the applied voltage.

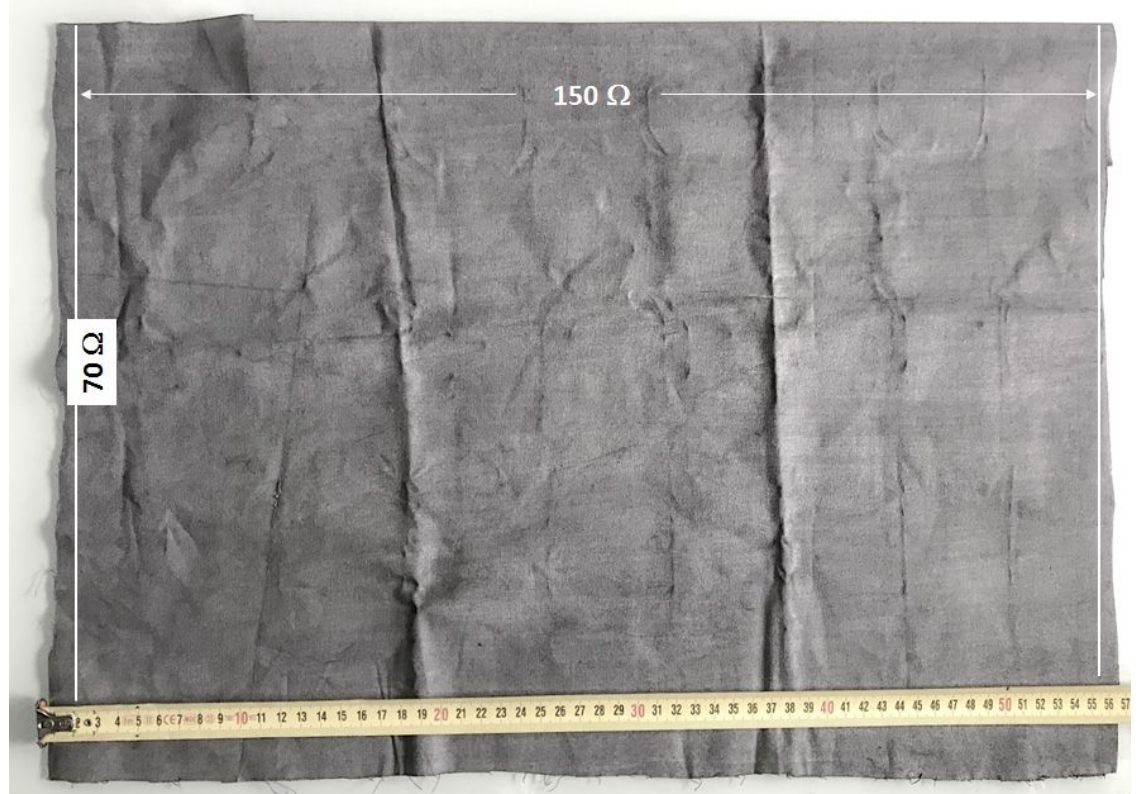

Figure S8. Digital photo of the FLG@CC composites with large dimension produced through dip-coating process with a FLG aqueous solution of $10 \mathrm{~g}$. $\mathrm{L}^{-1}$. The scrolled sample was oven dried at $130{ }^{\circ} \mathrm{C}$ for $2 \mathrm{~h}$. 


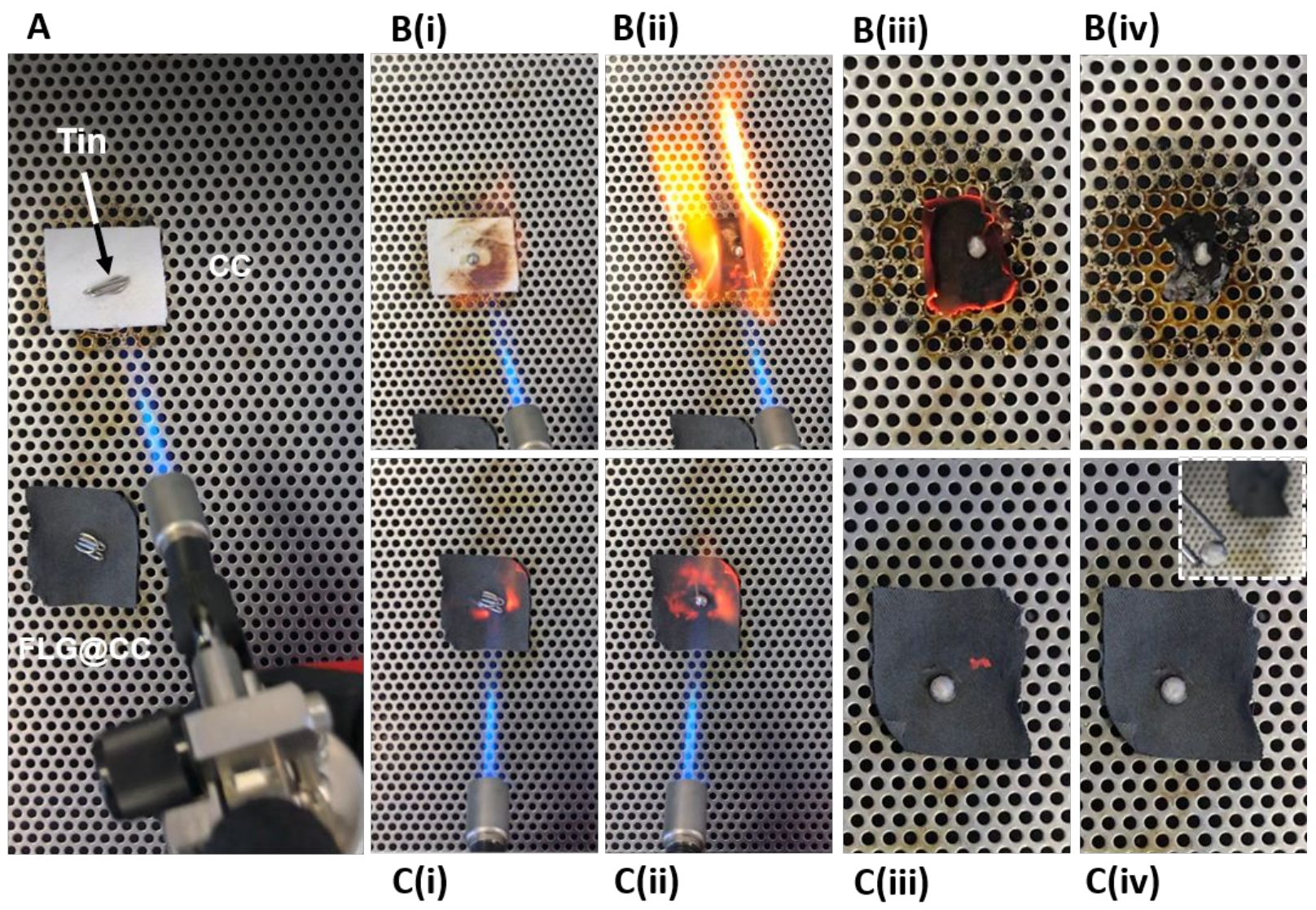

Figure S9. Experiments evidencing the high oxidative resistance of the FLG@CC composites. (A) Digital photos of a CC and FLG@CC composite (in this later the cotton cloth was thermally treated under argon at $400{ }^{\circ} \mathrm{C}$ for $2 \mathrm{~h}$ ) containing a tin rod. (B(i) to B(iv): Digital photos showing the complete combustion of the $\mathrm{CC}$ after contacting with a flame. (C(i) to C(iv): Digital photos showing the high combustion resistance of the FLG coated cotton cloth previously heat treated under argon. 


\begin{tabular}{|c|c|c|c|}
\hline \multicolumn{4}{|l|}{ Table S1. } \\
\hline & & position & $\%$ area \\
\hline \multirow[t]{5}{*}{ FLG } & $\mathrm{sp}^{2} \mathrm{C}$ and $\mathrm{sp}^{3} \mathrm{C}$ & 284.4 & 77.3 \\
\hline & $\mathrm{C}-\mathrm{O}$ or $\mathrm{C}-\mathrm{N}$ & 286 & 10.1 \\
\hline & $\mathrm{C}=\mathrm{O}$ & 287.4 & 4.5 \\
\hline & $\mathrm{O}-\mathrm{C}=\mathrm{O}$ & 289 & 4.2 \\
\hline & $\pi-\pi^{*}$ & 291 & 3.9 \\
\hline \multirow[t]{4}{*}{ TISSUE } & $\mathrm{sp}^{2} \mathrm{C}$ and $\mathrm{sp}^{3} \mathrm{C}$ & 284.4 & 6.4 \\
\hline & $\mathrm{C}-\mathrm{O}$ or $\mathrm{C}-\mathrm{N}$ & 285.9 & 46.2 \\
\hline & $\mathrm{C}=\mathrm{O}$ & 287.4 & 40.1 \\
\hline & $\mathrm{O}-\mathrm{C}=\mathrm{O}$ & 288.8 & 7.2 \\
\hline \multirow[t]{4}{*}{ FLG TISSUE } & $\mathrm{sp}^{2} \mathrm{C}$ and $\mathrm{sp}^{3} \mathrm{C}$ & 284.4 & 36.5 \\
\hline & $\mathrm{C}-\mathrm{O}$ or $\mathrm{C}-\mathrm{N}$ & 285.7 & 28.8 \\
\hline & $\mathrm{C}=\mathrm{O}$ & 287.3 & 24 \\
\hline & $\mathrm{O}-\mathrm{C}=\mathrm{O}$ & 289.4 & 10.7 \\
\hline
\end{tabular}

Table S1. Area and position of C 1s peak components of the 3 samples. 